\title{
An Agile Model for Assessing Quality of E-commerce Systems in Small and Medium Enterprises (SMEs) in Jordan
}

\author{
Sattam Rakan Allahawiah \\ Assistant professor, Department of Managerial and financial sciences \\ Albalqa Applied University, Karak University College, Jordan \\ E-mail: Sattam.amro@yahoo.com
}

Received: Dec. 3, 2012 Accepted: December 21, 2012 Published: January 1, 2013

doi:10.5296/jmr.v5i1.2791

URL: http://dx.doi.org/10.5296/jmr.v5i1.2791

\begin{abstract}
The significance of the study is that it addresses one of the vital issues of our time, it provides a model to evaluate the quality of e-commerce systems and electronic services are comprehensive, objective and flexible to reach the ideal model. The proposed model can be used to compare the quality of e-commerce systems, or to improve the image and performance of a particular e-commerce systems or to provide reference guide for designers of the sites where their determination to new sites.

To achieve the objectives of this study the researcher depended on two types of data: Secondary data: included reference books, periodicals and studies on the Internet. Primary data: included questionnaire designed for this purpose and was distributed over a sample study. For the purpose of testing hypotheses the study relied on statistical package for Social Sciences (SPSS) by using appropriate statistical methods. These are: Descriptive Statistic measures and Anova analysis test

Results of the study showed that there is an impact of technical attributes, managerial attributes, and human interface attributes on the performance and quality of e-commerce systems. According to the objectives and results of the study, researcher recommended a several recommendations such as, determine what the most effective means are to educate, inform, and motivate the Presidents, Owners, and managers of SMEs to take a proactive stance with regard to use and evaluate e-commerce system for business solutions
\end{abstract}

Keywords: Quality of E-commerce Systems, Technical attributes, Managerial attributes, Human interface attributes, Service quality, System transaction, System design 


\section{Introduction}

Past years have seen widespread of the Internet, huge number of websites and attendant dissemination of vast quantities of information, so we are suffering from a new phenomenon inflation information, and many sites without attention to quality and their services (Sean Quan Lau, 2006). The number of sites has grown since the start of first electronic trading mid-nineties of the last century. This explosion of knowledge of the number of sites led to the need for standards to ensure the quality of e-commerce systems and the services they offer. The main objective behind this number of sites is the continuous improvement of the performance of companies and the level of services they provide to the customers in the world of knowledge and the digital economy. The company's electronic site on the Internet, has a major impact on the company's performance, it has become in the world of e-business the core of the work of the companies and institutions that adopt the principle of electronic services. Therefore, firms and institutions are eager to make their best picture of the highest quality, with the aim of improving service, which contributes to the rosy picture given by the company will be reflected positively on its Performance.

E-commerce is considered an excellent alternative for companies to reach new customers. However, many e-commerce websites have a short life because they don't meet the minimal software quality requirements (Albuquerque and et al 2002). The tendency of major companies towards electronic commerce over the last decade, and the tremendous growth in the volume of electronic commerce based on the principle of electronic services, has led to concern in recent years the quality of e-commerce systems and the services they offer.

Ensuring the quality of e-commerce systems is not easy, standards which can determine that vary according to location and the nature of services provided. On this basis, we find many of the studies of the quality improvement websites on the service provided. Some researchers have gone to evaluate the quality of web sites for business and commercial companies, while others went to evaluate the quality of web sites for e-government sites (Ma and Zaphiris,2003, Choudrie et al 2004), while the others evaluated quality of banks and financial companies, as a number of researchers evaluated the quality of universities and educational institutions sites (singh and Sook, 2002). In addition, Other websites provide other types of services, such as web sites for auction, or e-shopping, and so on (Barnes and Vidgen, 2001). We have a variety of studies and researches based upon the diversity of web sites, the nature of services provided and the differences in the criteria used in the evaluation process, but what characterizes most of these studies is the use of descriptive style inalienable measure, and not to rely on quantitative style. In addition to previous studies that characterized most valuable improvement, particular type of e-commerce systems have provided a unified and comprehensive standards for all e-commerce systems and the services they offer.

Based on the foregoing, this study aims to analysis previous research studies, which dealt with evaluating the quality of e-commerce systems, and reaching a framework for evaluating the quality of e-commerce systems, regardless of the nature of the service provided by the electronic site, the framework contains all the key elements of inclusiveness, clarity and objectivity by the possibility of using the numerical values of the indicators for measuring 
process, and flexibility through the possibility of its application to all e-commerce systems, regardless of the nature of the service provided.

\section{Problem statement}

With the direction of major companies to online transactions and the growth of electronic commerce accelerating growth and entering the world economy, as one of the most important features of the modern digital economy, it has become incumbent upon companies and businesses and should pay more attention to the electronic services they provide. In spite of the continued growth of sites and the attendant electronic dissemination of vast quantities of information, whether high or low quality, it does not have very comprehensive standards serve as a basis for ensuring the quality of e-commerce systems and the services they offer. The quality of the e-commerce systems of the company and the services they offer over the Internet will reflect on their performance and help content of the information to give rosy picture for the company.

In the past few years, a large number of e-commerce systems have been developed. To ensure the production of high quality of e-commerce systems, it is important for developers to be able to assess the quality of such systems. The latter is inevitably linked with the receivers' perception of quality. It must be noted that e-commerce systems differ from other web applications in that a basic condition of their success is the total involvement of the end-user at almost every stage of the purchasing process (Henfridsson and Holmstrom, 2003), which is not the case with other web applications. The growth that business to Consumer (B2C) e-commerce systems have experienced in the past few years has given rise to the problem of identification of those factors that determine end-user acceptance of such systems (Chen et al., 2004).

A number of approaches towards assessing the quality attributes of e-commerce systems focus on the technological aspects of such systems, thus providing a technology-oriented view of quality (Zwass, 1996; Elfriede and Rashka, 2001). Other approaches assess the quality of e-commerce systems as perceived by the end-user, but focusing mainly on the usability of such systems. Such approaches use software evaluation methods such as inspection (Nielsen, 2000) and inquiry methods (Shaw and DeLone, 2002) in order to record end users' perception of usability. Studies on e-commerce systems quality also focus on more specific quality characteristics such as issues that warrant successful transactions (Bidgoli, 2002), maximize the perceived trustworthiness (Egger, 2001; Slyke et al., 2004), or ensure e-commerce systems reliability (Elfriede and Rashka, 2001). Although, all the above factors are affecting the quality of e-commerce systems and are prerequisites for their success, they are not the only ones that relate to e-commerce systems quality. In order to model e-commerce systems quality, a global approach is required combining all factors affecting quality. Some related works are using questionnaires to detect users' opinions, the data from which are statistically analyzed in order to lead in values measuring quality characteristics such as usability (Sauro \& Kindlund, 2005). This is a common practice, since users' opinion is very important for the assessment of e-commerce systems (Julian \& Standing, 2003), as well as the active involvement of users into the evaluation process (Henfridsson and 
Holmstrom, 2003; Chen et al., 2004). Therefore, it has become necessary to develop a framework to evaluate the quality of e-commerce systems; to measure the efficiency and effectiveness of the e-commerce systems to provide electronic services to the company.

\section{Importance of the study}

Companies and institutions in the light of globalization and competitiveness are seeking to improve their services, particularly electronic access to excellence. With the tremendous growth in the global digital transactions, the entry of electronic commerce strongly in global business dealings under acceleration, heated competition in the provision of electronic services, the companies are keen on achieving the principle of comprehensive quality and special electronic sites and services on the Internet. Thus, those sites become electronic firms, so it must give good impression about the company from the outset. The significance of the study is that it addresses one of the vital issues of our time, which is the current enormous revolution in information technology and communications, it provides a framework to evaluate the quality of sites and electronic services are comprehensive, objective and flexible to reach the ideal site. The proposed framework can be used to compare the quality of e-commerce systems, or to improve the image and performance of a particular e-commerce systems or to provide reference guide for designers of the sites where their determination to new sites.

\section{The objectives of the study}

This study aims to examine and analyze previous research studies that evaluated the quality of sites and electronic services, and then develop a framework inclusive in terms of the advantage it contains the elements of the main quality indicators. These elements and new indicators that are clear, measurable, and flexible to the possibility of their application on all sites and services provided by regardless of the nature of the company or institution. In addition, there are certain tentative objectives that will examine and investigate quality attributes of e-commerce systems.

1- Developing a comprehensive theoretical framework of quality attributes for assessing the sites of e-commerce systems.

2- Investigating the impact of quality attributes on the effectiveness and success of e-commerce systems.

3-Investigating the reliability of the system, system accuracy, flexibility, online response time and ease of use.

4- assessing the influence of quality attributes of e-commerce sites on the Use and Customer Satisfaction of e-commerce systems.

\section{Research Questions:}

The key questions that motivated our study are:

1. Is there a comprehensive framework of quality attributes for assessing the sites of e-commerce systems?. 
2. What are the quality attributes that must be available in such models?.

3. Do the current models provide a standardized for all involved parties and method for applying?.

4. How can we improve e-commerce systems to meet organizational effectiveness?

\section{Literature Review}

Many of the studies have addressed the quality of sites from several points of view, some dealt with in terms of quality characteristics of the e-commerce systems, which is sensitive and influential to the success of e-business, and it has been called "the critical success factors." Others considered quality in terms of strategies management to be followed to satisfy customers and to achieve their needs upon the use of electronic services, and the third group has addressed the quality of the sites from the perspective of the designers of sites and e-commerce systems, and a fourth team opined in their studies for the design of a general framework for measuring the quality of these systems.so.

Antonia Stefani1,et al (2007) in their study introduced to the reader a quality assessment model based on Bayesian Networks and presented in detail the practical application of this model, highlighting practical issues related to the involvement of human subjects, conflict resolution, and calibration of the measurement instruments. Furthermore, their paper presented the application process of the model for the quality assessment of various ecommerce systems; it also discussed in detail how particular features (data) of the assessed e-commerce systems can be identified and, using the described automated assessment process, lead to higher abstraction information (desire data) regarding the quality of the assessed e-commerce systems.

Antonia Stefani et al (2003) proposed a model based on the ISO 9126 quality standard specifically, it relies on the set of those quality characteristics and sub-characteristics that are directly related to quality as perceived by the end-users. These quality characteristics are: functionality, usability, reliability and efficiency. The importance of each of the above mentioned quality characteristics depends on each e-commerce system's specificities as well as the user requirements and developer priorities for the specific system.

Youngsu Lee and Jinwoo Ki(2000) suggested a comprehensive framework that covers from concrete design features to financial performance for online stock trading, which is one of the most important domains of e-business. The proposed model for online stock trading sites consists of three design principles: functional convenience, representational delight, and structural firmness. They found that the convenience, delight and firmness principles were closely related to the level of customer satisfaction, and, consequently, to the level of customer loyalty to the sites. They also identified important design features such as presentation of stock quotes in the homepage for each of the three design principles.

Wendy Cukier and Catherine A. Middleton (2003) in their study "Evaluating the web presence of voluntary sector organizations," examined how Canadian voluntary sector organizations have used their Web sites, they found that national Canadian voluntary 
organizations' Web sites were rated, using a standardized tool to assess organizational objectives and to evaluate functionality, navigation and aesthetics. These sites currently offer limited functionality, and many are not well-designed. The study showed lessons from information technology theory and practice to demonstrate how the functionality and design of voluntary sector Web sites (in Canada and elsewhere) can be improved, to better support organizational objectives and to reduce the "digital divide" between the profit and nonprofit sectors.

Krauss (2003) has mentioned key factors to evaluate the e-government sites. Yet others focused on a particular element, while Choudrie et al. (2004)have adopted the accessibility of information, quality, safety and privacy.

The study of Abanoumi and others (2005) have addressed three main areas, firstly, website accessibility guidelines; secondly, website accessibility tools and finally the implication of human factors in the process of implementing successful e-Government websites. Their study investigated the issues that make a website accessible and explored the importance placed on web usability and accessibility with respect to e-Government websites. They briefly examined accessibility guidelines, evaluation methods and analysis tools. And then evaluated the web accessibility of e-Government websites of Saudi Arabia and Oman by adapting the 'W3C Web Content Accessibility Guidelines'. Finally, they presented the following recommendations for improvement of e-Government website accessibility. (1) Governments in GCC countries need to review their accessibility related policies to accelerate the transition to accessible e-Government websites.(2) Website development requires different IT expertise in terms of accessibility, usability, security, user interface design.(3) Government should either adapt the existing web accessibility guidelines or develop its own guidelines that are appropriate for their context.(4) In general, governments need to understand the obstacles to making e-Government's websites accessible and should adopt the appropriate solution to improve it. (5) It is important to understand that all e-Government endeavours are critically dependent on the accessibility of its integral websites. If a website is not accessible to the intended target users, it will not be successful.

When reviewing studies that have addressed the sites for the quality of universities and educational institutions, we found that there are a significant number of these studies used a number of criteria to evaluate such sites from different points of view. Lautenbach et al (2006) used two standards: the ability to find information, and comprehensive information from a user's perspective, to evaluate the site of Aotrki University in the Netherlands, where the study concluded that: comprehensiveness of the information on the site, and easily created, namely basis in evaluating the sites of universities. Singh and Sook (2002) evaluated the sites of South African universities in terms of ease, features interactive, direct-site user, the relationship of information available on the site with the expectation of the student, and the rapid loading pages.

Turban and Gherke, ( 2000) suggested additional variables such as 24-hour availability, stability of software and hardware, page loading speed, the system architecture, visual appearance and accessibility as part of the e-commerce system quality. The model highlights 
that such attributes of e-commerce sites are likely to influence the Use and Customer Satisfaction of e-commerce systems.

Zhang and Dran (2003) have built a conceptual framework to assess the quality of university sites from the point of view of achieving the desire of the user, which used five criteria as the most important criteria for this purpose, namely: ease of navigation, provide a tool for research, information accuracy and completeness of information, the presentation of information and clarity.

It is noted by the survey of the studies and research conducted on evaluating the quality of sites and electronic services, the lack of Arab Studies on the subject. Defallah (2005) in his study on digital content Arab Internet sites between reality and prospects for development, the digital content Arab Internet sites threatened with collapse of the small contribution of Arab States production cognitive World on the Internet, and the widening gap between what is published in Arabic and published in other languages.

The study of Abdel-Hamid (2005) has addressed the problem of the quality of information in the websites of dissemination of useful information without any restrictions, as has been proposed a set of criteria to help users of the Internet, for distinguishing between different kinds of information to be able to select the best and most appropriate to the needs of the recipient. In his study Abdel Muti (2005), has adopted a topic on marketing information in the age of information and the importance of that institution, especially electronic marketing as the best way to do so.

The study of Chalabi and et al, (2005) have discussed the impact of the information revolution and communications technology and electronic services associated with the light of globalization on the education sector in Jordan. Some studies in other Arab sites evaluated the quality of university libraries on the Internet,for example, Gharib, (2006), conducted a comparison of the locations of some Arab and Western libraries in terms of quality in the provision of electronic services. Having pointed to the same content in terms of evaluating the quality of library sites on the Internet other studies, including the study of Omar (2006) dealt with the subject of several studies of e-government in a number of Arab countries, in terms of application and the obstacles and problems facing that without broaching the subject of quality.

According to Wolfinbarger and Gilly, (2000) Web site design needs to differentiate between the needs of goal-directed and experiential users [38]. They find that the majority of on-line buyers do not expect or desire high touch service, but are motivated by features that increase their sense of control and freedom, including order tracking, purchase histories, savings information, optional e-mail notification, and special deals

Luis Olsina Santos (1999),presented a methodology for the quantitative evaluation and comparison of Web site quality called Web-site Quality Evaluation Method (QEM). The core models and procedures for artifact evaluation are supported by the Logic Scoring of Preference (LSP) model and continuous preference logic as mathematical background. he discussed the process steps that the evaluators should follow by applying the Web-site QEM, 
namely: (a) Selecting a site or a set of competitive sites specific to a domain, (b) Specifying goals and the user view, (c) Specifying in a standard-compliant way, Web-site quality characteristics and attributes, (d) Defining the evaluation criterion for each attribute, and applying attribute measurement, (f) Aggregating elementary attributes to yield the global quality preference, and (g) Analyzing, assessing, and comparing partial and global outcomes. In order to illustrate the methodology he focus on a case study on typical museum sites where more than ninety components were involved regarding the general visitor view. The process results may be useful to understand, control, and improve the Web artifacts quality in small, medium and large-scale projects.

The 2QCV3Q, also called 7-loci, is a conceptual model proposed by Mich li and et al (2003) to evaluate web site quality based on seven dimensions: who-what-why-when-where-how, and feasibility (with what means and devices). It is interested and very flexible approach to evaluate a generic web site takes its name from the initials of the Ciceronian loci on which it is based, namely: Quis (Identity), Quid (Content), Cur (Services), Ubi (Location), Quando (Management), Quomodo (Usability), Quibus Auxiliis (Feasibility).

A more analytic web site quality model was proposed by Etnoteam (2000) It is based on six attributes (communication, content, functionality, usability, management, accessibility). The model can be personalized: the sub-attributes are weighted depending on the site category.

Correctness, presentation, content, navigation and interaction are the five dimensions considered by Oreste Signore (2005) quality model. The model has been designed to cover a possible automated process for the quality evaluation, using pages and page components as elements to evaluate. The first step in the quality assessment process is an automatic check of the source code, followed by manual evaluation.

\section{A proposed theoretical framework:}

The literature analysis of standards and quality evaluation of E-commerce systems showed that quality evaluation approaches suffer from several limitations, as follow:

- They often define very general criteria, do not address its specific websites (e-government, large public sites) or page (informative, directory, service specific, etc.). These differences must be taken into account when measuring the characteristics of the sites.

- The perception of the quality changes from different user perspectives: the final user is interested in external quality related to the usability and functionality of the site, while the developer is more interested to the internal quality related to backward and forward compatibility, openness to evolution, maintainability, portability, interoperability, etc.

- Customers' quality expectations change over time and thus no single quality checklist will be good for very long.

- Customers in a Web domain do not regard all quality factors as equally important.

- Many evaluation criteria are essentially accessibility or usability biased. Even if the two areas have some overlap, stressing one of them can be misleading. It occurs that a perfectly 
usable site is really not accessible, or that a technically accessible site may be scarcely usable.

Therefore, in this research I am going to propose a theoretical framework, this framework contains accurate and clear standards of objectivity, comprehensiveness and flexibility to assess the quality of e-commerce systems. The Proposed framework consists of three main elements, these elements are: technical attributes, managerial attributes, and human interface attributes, see figure (1). Each of these main elements has sub-attributes to evaluate the quality of e-commerce systems. Moreover, The Proposed framework can be used to improve the image and performance of particular e-commerce systems or to provide reference guide for designers of the sites.

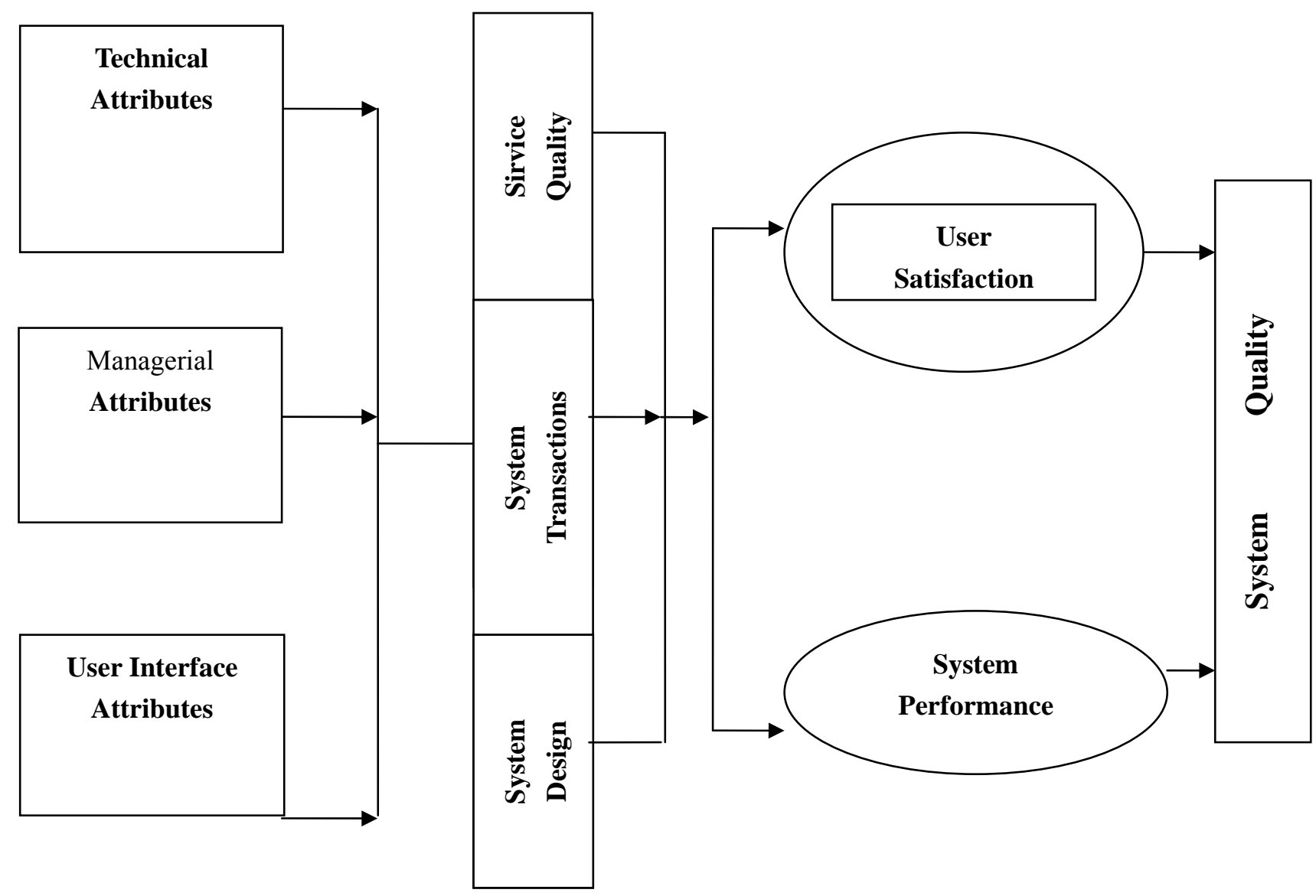

Figure 1. A proposed theoretical Framework

\section{Research Hypotheses:}

Based on the proposed framework, we will develop the following hypotheses:

- H1: Technical attributes is positively associated with service quality, system transaction and system design. 
- $\quad \mathrm{H} 2$ : Managerial attributes is positively associated with service quality, system transaction and system design.

- H3: Human interface attributes is positively associated with service quality system transaction and system design.

- $\quad$ H4: service quality positively affects user satisfaction and system performance.

- $\quad$ H5: system design positively affects user satisfaction and system performance. H6: System transaction positively affects user satisfaction and system performance.

- $\quad$ H7: user satisfaction positively affects system quality.

- $\quad$ H8: system performance positively affects system quality.

\section{Research Methodology:}

In order to investigate quality of e-commerce systems, a survey instrument developed to collect data to evaluate the hypotheses. Three sources of information were used to identify survey items: a review of the pertinent literature, questionnaires and online discussions with managers and developers,. The study has adapted the descriptive, field and analytic methods. A comprehensive survey and analyzing data that collected from questionnaires by using statistical ways were conducted to implement the field analytic research. The study based on a developed questionnaire that organized depending on the previous questionnaires; this questionnaire has adjusted to fit the Jordanian environment.

\section{Population of the study}

The study population contains from all SMEs in Jordan that work in main sectors and classified as the following: banks, insurance, industrial, services firms, and firms in other sectors. Which represent the individuals, managers, assistants' managers, and top managers in the listed firms.

\section{Sample of the study}

The sample contains of (50) firms which are banks, insurance, industrial, and services firms, as shown in the table (1) below. The simple random sample was selected from managers of banks, insurance, industrial, trading, services, and financial firms. The questions were responded by the responsible chairmen, managers, assistant managers, and employee in the mentioned companies.

\begin{tabular}{|l|l|}
\hline Institution/sector & Number of firms \\
\hline Banks sectors & 12 \\
\hline Services sector & 11 \\
\hline Insurance sector & 10 \\
\hline Manufacturing sector & 8 \\
\hline Other sectors & 9 \\
\hline Total & 50 \\
\hline
\end{tabular}

Sample of the study Table 1: 
It has chosen a convenient sample from the study population, the sample included total (400) observations, which were distributed to the respondents as the following: banks financial company (110), insurance (70), industrial (65), services firms (75), and other sectors (85), the returned questionnaires were (289); (27) questionnaires were excluded because they weren't valid for statistical analysis, so the valid questionnaires were $262(65 \%)$. Majority of questionnaires distributed on banks and financial firms, this return for several reasons:

- $\quad$ The rapid developments of technology in banking and financing sector.

- The growing role of banking sector in economy.

The both sector has a good quality of employees and managers.

\section{Constancy of the Instrument}

Constancy factor was calculated according to (Cronbach Alpha) for internal correspondence of total formulation and for each variable with all dimensions. The questionnaire was distributed to (3) subjects outside of the sample, the results as shown in table (1).

Table 1. Value of internal correspondence for each variable (independent and dependent) with all dimensions

\begin{tabular}{|l|l|l|}
\hline Number of paragraph & Variable and dimensions & $\begin{array}{l}\text { Constancy factor } \\
\text { Cronbach Alpha }\end{array}$ \\
\hline $1-15$ & Technical attributes & 0.93 \\
\hline $16-24$ & Managerial attributes & 0.87 \\
\hline $25-34$ & Human interface attributes & 0.90 \\
\hline $1-34$ & Overall average & 0.90 \\
\hline
\end{tabular}

The table shows that constancy factors are high and valid for statistical analysis and scientific research.

\section{Statistical Process}

To answer questions about the study and test the validity of hypotheses. Descriptive Statistic Analytical methods (by using SPSS. 13) were used.

1. Descriptive Statssts Measures were used to answer the question of the study and to organize the dimensions downwardly as well as to describe the characteristics of the sample by using percentages.

2. Multiple Regression Analysis was used in order to test the validity of the study and the effect of the independent variable and its dimensions in the dependent variable and its dimeminssions.

3. Analysis of test T. (One Sample Test) to test the impact of the independent variable on the dependent variable. 
4. Stepwise Multiple Regression Analysis was used for using the independent variables in predicting equation of dependent variable.

5. Variance inflation Factory (VIF) and Tolerance were used for insuring that there is no high correlation between the independent variables.

6. Skewness was used in order to insure that data follows the normal distribution.

\section{Instrument Validity}

The validity of the questionnaires was constructed by reviewing each of its questions by the supervisor and professional doctors at al balsa applied university and some Jordanian Universities. To verify the validity of the paragraphs of questionnaires, remarkable amendments have been made to reformulate some of the paragraphs, and the required adjustments. The results were achieved accurately to maintain a balance between the contents of questionnaires and its paragraphs. The following checklist was used to review the questionnaire instrument:

- Will the words be uniformly understood?

- Do the questions contain abbreviations or unconventional phrases?

- Are the questions too vague?

- Is the question too precise, biased or objectionable?

- Is it a double-barrel question?

Does it have a double negative?

- Are the answer choices mutually exclusive?

- Has too much knowledge been assumed?

- Is the question technically accurate?

- Are the questions too cryptic?

\section{Research Assumptions}

To ignore any other influential factors, which may affect the results of this study, the following can be assumed as research assumptions:

1-The selected sample was assumed to be a suitable representation of the study population.

2- The respondents was assumed understand every question in the study tool, and answered precisely and honestly.

3-The instrument and statistical techniques were effective, valid, and suitable for this kind of studies.

\section{Characteristics of the respondents}

The purpose of this study was to assess the current state of evaluate the quality of e-commerce systems by SMEs in Jordan. Therefore, the results of this study are presented 
and analyzed in this section. The study used a descriptive analysis to describe the characteristics of the respondents. The research hypotheses were presented and tested, ANOVA was used to measure the differences between the sample groups, Pearson Correlation was used to explore the correlation between the study variables (dependent and independent variables), and Stepwise multiple regression was used to test the hypotheses.

Gronbach Alpha was used to ensure the reliability of answering, and the result of this coefficient is $(89.7 \%)$ which reflected a homogenous response of the study sample. The first section in this study presents a summary of the data collection process. The second section summarizes the descriptive analysis and findings regarding the survey responses. The third section reviews the data analysis by major hypothesis

Table 2. Description of the characteristics of a study sample

\begin{tabular}{|l|l|l|l|}
\hline Gender & frequency & Percent & Cumulative percent \\
\hline Female & 80 & $30.5 \%$ & 30.5 \\
\hline Male & 182 & $69.5 \%$ & 100 \\
\hline Total & 262 & 100.0 & \\
\hline
\end{tabular}

Table (2) indicates that $30.5 \%$ of the study sample are female, and the remaining $(69,5 \%)$ respondents male. These findings show that the most employees in the listed firms are from men and the reason might be to the nature of the companies in these sectors

Table 3. Characteristics of the respondents: Age

\begin{tabular}{|l|l|l|l|}
\hline Age & Frequency & percent & Cumulative percent \\
\hline Less than 20 years & 39 & $\% 14.9$ & 41.9 \\
\hline $21-35$ years & 77 & $\% 29.4$ & 44.3 \\
\hline 36-50 years & 106 & $\% 40.5$ & 84.8 \\
\hline More than 50 & 40 & $\% 15.2$ & 100.0 \\
\hline Total & 262 & 100.0 & \\
\hline
\end{tabular}

Table (3) shows that $14.9 \%$ of the study sample is less than 20 years, $29.4 \%$ is between $21-35$ year, $40.5 \%$ is between $36-50$ year, and $15.5 \%$ older than 50 years. The findings of this table show that few of the respondents were from the first level and the majority of the respondents lie in the third level. 
Table 4. Characteristics of the respondents: Experience

\begin{tabular}{|l|l|l|l|}
\hline Experience & frequency & Percent & Cumulative percent \\
\hline Less than 2 years & 37 & $14.1 \%$ & 14.1 \\
\hline 3-6 years & 70 & $26.7 \%$ & 40.8 \\
\hline 7-10 years & 121 & $46.2 \%$ & 87.0 \\
\hline More than 10 years & 34 & $13.0 \%$ & 100.0 \\
\hline Total & 226 & 100.0 & \\
\hline
\end{tabular}

Table (4) clarifies that $14.1 \%$ of the respondents whom have less than two years experience, $26.7 \%$ whom have an experience between 3-6 years, $46.2 \%$ whom have an experience between 7-10 years, and 13\% whom have an experience more than 10 years. The findings showed that the least respondents are from the last level, and the majority of the respondents whose years of experience lay between seven and ten.

Table 5. Characteristics of the companies: Number of employee

\begin{tabular}{|l|l|l|l|}
\hline Number of employee & Frequency & percent & Cumulative percent \\
\hline Less than 10 employee & 44 & $15.2 \%$ & 15.2 \\
\hline Between10-49 & 78 & $26.9 \%$ & 42.1 \\
\hline Between50-249 & 140 & $48.4 \%$ & 90.5 \\
\hline More than 250 & 27 & $9.5 \%$ & 100.0 \\
\hline Total & 262 & 100.0 & \\
\hline
\end{tabular}

Table (5) indicates that there are different variables that show characteristics of the respondents. Firstly, less than ten employees occupied $15.2 \%$ of the respondents. Secondly, the employee between 10-49 have carried $26.9 \%$ of the respondents. Thirdly, the employee between 50-249 have got $49.4 \%$ of the respondents. Finally, the employee more than 250 have occupied less percentage of the different variables. Thus, the last value is going to be excluded of our study as it is not within the group of our selected firms. However, the majority of the respondents are from 50-249.

Table 6. Characteristics of the companies: sectors

\begin{tabular}{|l|l|l|l|}
\hline Sectors & Frequency & percent & Cumulative percent \\
\hline Financial and banking & 66 & $25.1 \%$ & 25.1 \\
\hline Insurance & 55 & $20.9 \%$ & 46.0 \\
\hline Services & 54 & $20.6 \%$ & 66.6 \\
\hline Manufacturing & 47 & $17.9 \%$ & 84.5 \\
\hline Others & 40 & $15.5 \%$ & 100.0 \\
\hline Total & 262 & 100.0 & \\
\hline
\end{tabular}


Table (6) illuminated that there are respondents from different sectors. Firstly, Financial and banking sector occupied $25.1 \%$ of the sample. Secondly, Insurance sector has carried $20.9 \%$ of the sample. Thirdly, the Services sector has got $20.6 \%$ of the sample. Fourthly, manufacturing sector has got $17.9 \%$ of the sample. Finally, the other sectors have occupied $15.5 \%$ of the sample. Consequently, the different variables were close in ratio to each other.

Table 7. Characteristics of the respondents: Job level

\begin{tabular}{|l|l|l|l|}
\hline Job level & Frequency & Percent & Cumulative percent \\
\hline Manager & 124 & $47.3 \%$ & 47.3 \\
\hline Manager assistant & 38 & $14.5 \%$ & 61.8 \\
\hline Branch chief & 35 & $13.4 \%$ & 75.2 \\
\hline Employee & 65 & $24.8 \%$ & 100.0 \\
\hline Total & 262 & 100.0 & \\
\hline
\end{tabular}

Table (7) indicates that $47.3 \%$ of the respondents are from managers. $14.5 \%$ of the respondents are from manager assistant, $13.4 \%$ of the respondents are from branch chief, and $24.8 \%$ of the respondents are from employees. Therefore, the findings showed that the big ratio $(47,3 \%)$ of the respondents is from managers. And I think the participation of managers in this study will create validation for it.

\section{Testing Hypotheses}

Before using regression analysis to test hypotheses, some tests have been conducted in order to insure that data are valid for regression analysis hypotheses. For the hypothesis, multicollinearity between independent varialbes must not be found, the researcher conducted Variance Infation Factor (VIF) and Tolerance test for each variables of independent variables. Table (9) indicates that if (VIF) for the variable over (10) and the value of acceptable variation was less than (0.05), it could say that this variable has high correlation with other independent variables which causes a problem to regression analysis. Testing Multicollinearity between variables was based on this rule. From the table (9), which contains values of (VIF) and Tolerance for each variable, we can see that (VIF) value for all variables was less than (10) and ranged (2.692 - 4.190); also we can notice that variation value for all variables was more than $(0.05)$ and ranged $(0.239-0.405)$, so we can say that there is no serious problem related to existence multicollinearity between dependent variables. 
Table 8. Values of VIF, Tolerance and Skewness tests

\begin{tabular}{|l|l|l|l|}
\hline Variables & Tolerance & ) VIF ( & Skewness \\
\hline Technical attributes & 0.372 & 2.692 & 0.207 \\
\hline Managerial attributes & 0.345 & 2.896 & 0.210 \\
\hline Human interface attributes & 0.239 & 4.190 & 0.159 \\
\hline Problems & 0.405 & 2.768 & 0.457 \\
\hline
\end{tabular}

Calculating Skewness value for all variables was used to test Normal Distribution hypothesis. Table (8) shows that Skewness coefficient value for all variables of study was less than (.05), so it is possible to say that there is no problem related to normal distribution. Models' validity for each hypothesis will be verified separately.

The following are the results of statistical analysis of the data, relying on analysis of test $\mathrm{T}$. (One Sample Test) to test the impact of the independent variable on the dependent variable is the value of mathematical averages and standard deviations, and arranged to study all dimensions, and paragraphs after each component, taking into account the measure to include user In the study as follows:

\begin{tabular}{|l|l|l|l|l|}
\hline strongly Disagree & Disagree & Undecided & Agree & Strongly Agree \\
\hline$(1)$ & $(2)$ & $(3)$ & $(4)$ & $(5)$ \\
\hline
\end{tabular}

According to the arithmetic averages values they had reached the study, will be dealt with the interpretation of the data as follows:

\begin{tabular}{|l|l|l|}
\hline Low & Medium & High \\
\hline $2.49-1$ & $3.49-2.5$ & 3.5 and above \\
\hline
\end{tabular}

Accordingly, if the arithmetic mean value of the paragraphs of the largest (3.5) would be very high impact, but if the value of arithmetic mean (2.5-3.49) is revoked, the average severity of impact and, if less than the arithmetic average (2.49) is revoked, it would affect low-intensity. 3.5 And over. The decision rule for the test is to reject the null hypotheses, and accept the alternative hypotheses if the calculated (t- Sig) is less than 0.05. According to the decision rule: Accept Ho if T. sig. $>.05$ and Reject Ho if T. sig. $<.05$

Ho. (1): Technical attributes is positively associated with service quality, system transaction and system design 
Table 9. Analysis of test results T. (One Sample Test) to test the impact Technical attributes in service quality, system transaction and system design

\begin{tabular}{|l|l|l|l|l|l|l|}
\hline Technical attributes & Mean & Std & Rank & Severity & T.Value & Sig \\
\hline Integration to databases and other IS & 3.62 & 0.51 & 4 & high & $* 19.777$ & 0.000 \\
\hline Correctness & & & & & & \\
\hline Reliability & 3.57 & 0.50 & 6 & high & $17.961 *$ & 0.000 \\
\hline Efficiency & 3.56 & 0.58 & 7 & high & $15.898 *$ & 0.000 \\
\hline Integrity & 3.65 & 0.60 & 2 & high & $17.531 *$ & 0.000 \\
\hline Security & 3.71 & 0.59 & 1 & high & $19.172 *$ & 0.000 \\
\hline Reusability & 3.64 & 0.55 & 3 & high & $17.866 *$ & 0.000 \\
\hline Portability & 3.62 & 0.51 & 4 & high & $* 19.777$ & 0.000 \\
\hline Maintainability & 359 & 0.57 & 5 & high & $18.762 *$ & 0.000 \\
\hline Overall average & 3.64 & 0.55 & 3 & high & $17.866 *$ & 0.000 \\
\hline & 3.62 & 0.47 & - & high & $* 29.73$ & 0.000 \\
\hline
\end{tabular}

* Statistically significant level $(\leq 0.05) \alpha$

The above table elucidates that the overall average impact of Technical attributes in service quality, system transaction and system design on small and medium enterprises in Jordan is high, it reached (3.62), the standard deviation (0.47), which indicates that the impact of Technical attributes on system quality in small and medium enterprises in Jordan and it has got a high degree, so, the first dimension (Integrity) occupied first rank with average( 3.71 ), followed by dimension (Efficiency) with average (3.65), dimensions (Security)and (Maintainability) came in third with average (3.64), the dimensions (Integration to databases and other IS)( Reusability) came in fourth place with average (3.62), while the dimension (Correctness) was ranked fifth with average (3.57). Dimension (Reliability) came in last rank with average (3.56). Thus, the researcher has noticed that all values of $(t)$ were calculated at the level of $(\alpha \geq 0.05)$, and therefore we reject the null hypothesis and accept the alternative hypothesis, which provides that e-commerce influences positively on the reduction of market pressures and economic pressures in small and medium enterprises in Jordan.

Ho. (2): Managerial attributes is positively associated with service quality, system transaction and system design 
Table 10. Analysis of test results T. (One Sample Test) to test the impact of Managerial attributes in service quality, system transaction and system design on small and medium enterprises in Jordan

\begin{tabular}{|l|l|l|l|l|l|l|}
\hline Managerial attributes & Mean & Std & Rank & Severity & T.Value & Sig \\
\hline Clients' needs & 3.61 & 0.97 & 3 & high & $* 10.244$ & 0.000 \\
\hline Clients' satisfaction & 3.76 & 1.08 & 1 & high & $* 11.462$ & 0.000 \\
\hline Clear EC strategy and goals & 3.53 & 0.95 & 6 & high & $* 9.084$ & 0.000 \\
\hline Cost effectiveness & 3.59 & 1.04 & 4 & high & $* 9.161$ & 0.000 \\
\hline Business expectations & 3.68 & 0.99 & 2 & high & $* 11.081$ & 0.000 \\
\hline EC application justification & 3.55 & 1.03 & 5 & high & $* 8.638$ & 0.000 \\
\hline $\begin{array}{l}\text { Accurate and timely information (supplying on-time } \\
\text { response) }\end{array}$ & 3.59 & 1.04 & 4 & high & $* 9.161$ & 0.000 \\
\hline $\begin{array}{l}\text { Others (management changes, EC policy and ethics, } \\
\text { training, target audience, etc.) }\end{array}$ & 3.53 & 0.95 & 6 & high & $* 9.084$ & 0.000 \\
\hline $\begin{array}{l}\text { Overall average } \\
\text { nater }\end{array}$ & 3.62 & 0.51 & - & high & $* 19.777$ & 0.000 \\
\hline
\end{tabular}

* Statistically significant level $(\leq 0.05) \alpha$

Table (10) explicates that the respondents' perceptions level toward Managerial attributes in small and medium enterprises in Jordan play a major role, it has been of a high level with average (3.62), the standard deviation (0.51). Thus, it indicates that the Managerial attributes in in Small and medium enterprises in Jordan has been of a high degree, so, the second paragraph (Clients' satisfaction) occupied first rank with average( 3.76), followed by paragraph (Business expectations) with average (3.68) And there is a strongly agreement that Clients' needs, this paragraph came in third level with average (3.61), then followed by paragraphs (Cost effectiveness)and(Accurate and timely information (supplying on-time response) with average (3.59), while paragraph (EC application justification) came in fifth rank with average (3.55). Finally paragraph (Clear EC strategy and goals)and (policy and ethics, training, target audience, etc). came in last rank with average (3.53). Consequently, the researcher has found that all values ( $t)$ were calculated at the level of $(\alpha \geq 0.05)$. 
Ho. (3): Human interface attributes is positively associated with service quality, system transaction and system design

\begin{tabular}{|c|c|c|c|c|c|c|}
\hline Human interface attributes & Mean & Std & Rank & Severity & T.Value & Sig \\
\hline Intuitive & 3.58 & 0.66 & 6 & high & $12.853 *$ & 0.000 \\
\hline On-line help and assistance & 3.60 & 0.64 & 5 & high & $13.438 *$ & 0.000 \\
\hline Easy of use (sophisticated search capabilities) & 3.69 & 0.52 & 1 & high & 23.828 & 0.000 \\
\hline User friendly (use different media types) & 3.57 & 0.65 & 7 & high & $14.482 *$ & 0.000 \\
\hline Multilingual (support several languages) & 3.63 & 0.57 & 3 & high & $14.679 *$ & 0.000 \\
\hline Easy to understand (avoid ambiguous term) & 3.61 & 0.65 & 4 & high & $15.174 *$ & 0.000 \\
\hline $\begin{array}{l}\text { Easy to change information in case of erroneous data } \\
\text { being entered in the business form) }\end{array}$ & 3.66 & 0.83 & 2 & high & *13.361 & 0.000 \\
\hline $\begin{array}{l}\text { Others (Quick feedback on the transaction being } \\
\text { processed, customer loyalty, etc.) }\end{array}$ & 3.58 & 0.66 & 6 & high & $12.853 *$ & 0.000 \\
\hline Overall average & 3.62 & 0.50 & - & & $* 24.28$ & \\
\hline
\end{tabular}

* Statistically significant level $(\leq 0.05) \alpha$

Table (11) elucidates that the overall average impact of Human interface attributes in the system quality in small and medium enterprises in Jordan is high (3.62), the standard deviation (0.50). It indicates that the impact of Human interface attributes in Small and medium enterprises in Jordan have been of a high degree.

Many respondents agreed with the statement that (Easy of use (sophisticated search capabilities)) is a possible reason which might have motivated the organization to implement e-commerce systems. It occupied first rank with average (3.69), followed by dimension (Easy to change information in case of erroneous data being entered in the business form)) with average (3.66), dimension (Multilingual (support several languages)) came in third with average (3.63), while dimension (Easy to understand (avoid ambiguous term) was the fourth rank with average (3.61), although the respondents agreed with the dimension (On-line help and assistance) came in the fifth place with average (3.60). dimensions (Intuitive)and(Others (Quick feedback on the transaction being processed, customer loyalty, etc.) occupied sixth rank with average (3.58). Finally dimension (User friendly (use different media types)) came in the last rank with average (3.57). The researcher in this study has opined that all values of $(t)$ were calculated at the level of $(\alpha \geq 0.05)$. Therefore we reject the null hypothesis and accept the alternative hypothesis which provides that Human interface attributes has a positive impact in system quality in SMEs in Jordan.

Ho. (4): System transaction positively affects user satisfaction and system performance. 
Table 12. Analysis of test results T. (One Sample Test) test to increase innovation and new technology to reduce pressures on the technology small and medium enterprises in Jordan

\begin{tabular}{|l|l|l|l|l|l|l|}
\hline System transactions & Mean & Std & Rank & Severity & T.Value & Sig \\
\hline $\begin{array}{l}\text { Helped our employees to access and improved the } \\
\text { internal communication, transactional systems or both }\end{array}$ & 3.58 & 0.97 & 4 & high & $* 7.966$ & 0.000 \\
\hline Knowledge sharing with companies in network & 3.71 & 0.86 & 2 & high & $* 10.098$ & 0.000 \\
\hline Secure and reliable transactions & 3.72 & 0.79 & 1 & high & $* 10.886$ & 0.000 \\
\hline Overall average & 3.65 & 0.62 & - & high & $16.088 *$ & 0.000 \\
\hline $\begin{array}{l}\text { Correct and accurate information } \\
\text { about the products }\end{array}$ & & & & & & \\
\hline
\end{tabular}

* Statistically significant level $(\leq 0.05) \alpha$

Table (12) indicates that the factor System transactions in small and medium enterprises in Jordan is high (3.65), the standard deviation (0.62). It indicates that System transactions to increase user satisfaction in the Small and medium enterprises in Jordan have been of a high degree. The paragraph (created a new way to sell our products and services) attained high ratio with average (3.72), followed by paragraph (led to the sharing of knowledge with the companies on the Internet) with average (3.71), while paragraph (led to a better and easier interaction with customers and suppliers) came in the third rank with average (3.60). Finally paragraph (Helped our employees to access and improved the internal communication, transactional systems or both) came in the last level with average (3.58). Consequently, we noted that all values of $(t)$ were calculated at a level of $(\alpha \geq 0.05)$.

Ho. (5): Service quality positively affects user satisfaction and system performance.

Table 13. Analysis of test results T. (One Sample Test) test the impact of Service quality on user satisfaction and system performance in small and medium enterprises in Jordan.

\begin{tabular}{|l|l|l|l|l|l|l|}
\hline Service quality & Mean & Std & Rank & Severity & T.Value & Sig \\
\hline Improved operational efficiency within our organization & 3.59 & 0.80 & 2 & high & $* 11.711$ & 0.000 \\
\hline The system improve our customer service. & 3.55 & 0.89 & 4 & high & $* 10.114$ & 0.000 \\
\hline $\begin{array}{l}\text { Easy access to the web pages of the e-commerce } \\
\text { system. }\end{array}$ & 3.56 & 0.77 & 3 & high & $* 11.812$ & 0.000 \\
\hline Show high level of reliability in customer support & 3.73 & 0.86 & 1 & high & $* 13.855$ & 0.000 \\
\hline Easy navigation. & 3.50 & 0.91 & 6 & high & $* 9.980$ & 0.000 \\
\hline Better and direct service for the frequent User & 3.52 & 0.89 & 5 & high & $* 9.646$ & 0.000 \\
\hline Overall average & 3.57 & 0.65 & - & & $14.482 *$ & \\
\hline
\end{tabular}

* Statistically significant level $(\leq 0.05) \alpha$ 
Table (13) explicates that the variable of Service quality has attained a high ratio with average (3.57), the standard deviation is (0.65). This indicates that the growing importance of Service quality of enterprises to increase the user satisfaction and system performance in small and medium enterprises in Jordan. The respondents' perceptions level towards the paragraphs in this table is classified as follow; Firstly, the paragraph (Improved operational efficiency within our organization) it occupied the first with average( 3.73), followed by paragraph (The system improve our customer service) with average (3.59), the next paragraph is (Easy access to the web pages of the e-commerce system.) it came in third place with average (3.56), the fourth paragraph is (Show high level of reliability in customer support) with average (3.55), while paragraph (Easy navigation.) came in the fifth place with average (3.52). The final paragraph is (Better and direct service for the frequent User) came in last rank with average (3.50). The researcher in this study has examined all values of $(t)$ and they were calculated at the level of $(\alpha \geq 0.05)$.

Ho. (6): system design positively affect user satisfaction and system performance.

Table 14. Analysis of test results T. (One Sample Test) to test the impact of system design on user satisfaction and system performance in small and medium enterprises in Jordan.

\begin{tabular}{|l|l|l|l|l|l|l|}
\hline system design & Mean & Std & Rank & Severity & T.Value & Sig \\
\hline Clear use of color and background & 3.75 & 0.82 & 1 & high & $* 14.620$ & 0.000 \\
\hline $\begin{array}{l}\text { Chance to preview content } \\
\text { without registration/membership }\end{array}$ & 3.53 & 0.80 & 5 & high & $* 10.713$ & 0.000 \\
\hline Good signposts at all times & 3.72 & 0.84 & 2 & high & $* 14.791$ & 0.000 \\
\hline Different ways to get straight to where you want to go & 3.55 & 0.79 & 4 & high & $* 11.275$ & 0.000 \\
\hline Opportunity for customers/Users to give feedback & 3.66 & 0.83 & 3 & high & $* 13.361$ & 0.000 \\
\hline Overall average & 3.64 & 0.55 & - & high & $* 17.866$ & 0.000 \\
\hline
\end{tabular}

* Statistically significant level $(\leq 0.05) \alpha$

Table (14) clarifies that the overall average of the impact of system design are being used to increase system performance in small and medium enterprises in Jordan, it reached a high level with average (3.64), the standard deviation (0.55), which indicates that the impact of system design in increasing the user satisfaction and system performance in small and medium enterprises in Jordan have been of a high degree. The next paragraphs are being arranged in this order, the first one is Clear use of color and background) it occupied the first rank with average (3.75), followed by paragraph (Chance to preview content without registration/membership ) with average (3.72) The paragraph (Good signposts at all times) came in third level with average (3.66), while paragraph (Different ways to get straight to where you want to go) came in fourth place with average (3.55). The final paragraph is (Opportunity for customers/Users to give feedback) came in last rank with average (3.53). The researcher in this study has examined all values of $(t)$ and they were calculated at the level of $(\alpha \geq 0.05)$. 
Ho. (7): User satisfaction positively affect system quality.

Ho. (8): System performance positively affect system quality.

Table 15. Analysis of test results T. (One Sample Test) to test the impact of Technical attributes, Managerial attributes and Human interface attributes on quality of e-commerce systems in small and medium enterprises in Jordan

\begin{tabular}{|l|l|l|l|l|l|l|}
\hline Factors & Mean & Std & Rank & Severity & T.Value & Sig \\
\hline User satisfaction & 3.62 & 0.47 & 2 & high & $* 29.73$ & 0.000 \\
\hline System performance & 3.61 & 0.50 & 3 & high & $* 24.28$ & 0.000 \\
\hline Overall average & 3.615 & 0.49 & - & high & $* 26.38$ & 0.000 \\
& & & & & & \\
\hline
\end{tabular}

* Statistically significant level $(\leq 0.05) \alpha$

It can be seen from Table (15) that the overall average impact of User satisfaction on quality of e-commerce systems in small and medium enterprises in Jordan is high (3.63), the standard deviation (0.49), which indicates that user satisfaction has been ranked of a high degree, and occupied first average(3.67), and system performance with average (3.62). As such, all values of $(t)$ were calculated at the level of $(\alpha \geq 0.5$, therefore we reject the null hypothesis and accept the alternative hypothesis, which provides that Technical attributes, Managerial attributes and Human interface attributes has a positive impact on quality of e-commerce systems in small and medium enterprises in Jordan. Therefore, these attributes has been adopted by SMEs in Jordan as an affective factor in influencing on the system quality according to respondents opinions. The result suggests that the owners should pay attention to the policy of adopting these factors.

\section{Analysis of Hypothesis}

In addition to the descriptive analysis applied in order to understand better the characteristics of the sample, statistical tests were used to examine the relation between the independent variable. Following is a review of each hypothesis:

Hypothesis (1): Stated that technical attributes is positively associated with service quality, system transaction and system design.

A single population proportion test was performed to determine the statistical significance of the extent of effect of technical attributes on service quality, system transaction and system design in SMEs in Jordan. The results of the testing of hypothesis 1 are presented. The test was significant at the 0.01 level. The researcher, therefore, rejected the null hypothesis and accepted the alternative hypothesis. The research findings support the hypothesis 1 . It has been noted that the variable Integrity came in the first rank, therefore we conclude that using e-commerce systems in SMEs positively effect on systems quality. 
When comparisons are made between the reasons that may have motivated the SMEs to implement e-commerce systems and those of benefits that respondents experienced since implementing e-commerce systems, similarities are observed. For example, a majority of respondents indicated that Efficiency was both a driver as well as a benefit; a majority agreed that Security was both a motivator for implementing e-commerce systems as well as a benefit, and a majority strongly agree that Reliability was both a motivator as well as an experienced benefit.

Hypothesis (2): stated that Managerial attributes is positively associated with service quality, system transaction and system design.

From sample of 262 employees, we examined the effect of Managerial attributes on service quality, system transaction and system design, measured by eight factors: Clients' needs, Clients' satisfaction, Clear EC strategy and goals, Cost effectiveness, Business expectations, EC application justification, EC application justification, Others (management changes, EC policy and ethics, training, target audience, etc.) The results of the (One Sample Test) to test the hypothesis 2 were presented in Table 18. Because the value is calculated at the level of ( $\alpha$ $\geq 0.01$ ), the researcher rejected the null hypothesis and accepted the alternative hypothesis. The results of this hypothesis indicate that even though a majority of respondents agreed with the statement that (Managerial attributes.) is a possible reason which might have motivated the organization to implement e-commerce systems. For example, using the website can gain new contracts with suppliers and costumers; this racing the market share for these companies, furthermore, the reliability of credit card, and Legal structures are the main reasons that motivate the SMEs to move towards electronic business to maintain their own competitive position.

As well as the Clients' needs, the respondent agreed with other factors, but it not have high degree such as, growing importance of Clients' needs Based on the findings above, the managerial attributes affect business activities. Significant changes in any of these factors are likely to create business processes. To increase the systems performance the researcher found that implementing e-commerce systems is suitable way for SMEs to compete the large firms and maintain their own competitive position.

Hypothesis 3: stated that Human interface attributes is positively associated with service quality, system transaction and system design.

A single population proportion test was performed to determine the statistical significance of the extent of effect Human interface attributes on service quality, system transaction and system design in SMEs in Jordan. Similarly, Human interface attributes divided into eight questions: Intuitive, On-line help and assistance, Easy of use (sophisticated search capabilities), User friendly (use different media types), Multilingual (support several languages), Easy to understand (avoid ambiguous term), Easy to change information in case of erroneous data being entered in the business form), and Others (Quick feedback on the transaction being processed, customer loyalty, etc.). The results of the (One Sample Test) to test the hypothesis 3 were presented in Table 25. Because the value is calculated at the level of $(\alpha \geq 0.01)$, the researcher rejects the null hypothesis and accepts the alternative hypothesis. 
The research findings support the hypothesis3. Results from the structural analysis indicate that majority of the respondents have agreed with human interface attributes. Regarding, the factor human interface attributes and new technology the resulted showed that a majority of respondents perceive the benefits of e-commerce systems to SMEs, the systems created a new way to sell products and services. Therefore we found these reason is the most important determinants of the companies that paid to the adoption of e-commerce systems. Based on the findings above, it is clear that SMEs adopt e-commerce systems to increase revenue, increase range of products and services, establish better control over their customer and supplier relationships, and gain strategic advantage over their competitors.

Hypothesis (4): stated that System transaction positively affects user satisfaction and system performance.

A single population proportion test was performed to determine the statistical significance of the extent of effect System transaction positively affects user satisfaction and system performance.. The results of the testing of hypothesis 4 are presented. The test was significant at the 0.01 level. The researcher, therefore, rejected the null hypothesis and accepted the alternative hypothesis. The research findings are statistically significant in the explanation of the extent of System transaction by SMEs for business solutions and support the hypothesis that a majority use the sytem transaction for increasing systems quality. Feedback was provided pointing out that all the factors are important and suggested that managers perceived the benifite of e-commerce system quality. In other words, these attributes $\mathrm{s}$ influenced the decision to adopt or not to adopt e-commerce systems. Either, when comparisons are made between the reasons that may have motivated the organization to implement e-commerce systems and those of benefits that respondents experienced since implementing e-commerce systems similarities are observed.

Hypothesis (5): stated that Service quality positively affects user satisfaction and system performance.

We examined the effect of Service quality on user satisfaction and system performance. measured by six factors: Improved operational efficiency within our organization, The system improve our customer service, Easy access to the web pages of the e-commerce system, Show high level of reliability in customer support, Easy navigation,, Better and direct service for the frequent User. The results of the (One Sample Test) to test the hypothesis 5 were presented in Table 18. Because the value is calculated at the level of $(\alpha \geq 0.01)$, the researcher rejected the null hypothesis and accepted the alternative hypothesis. The results of this hypothesis indicate that even though a majority of respondents agreed with the statement that (Service quality) is a possible reason which might have motivated the organization to implement e-commerce systems. Based on the findings above, the service quality affect on system quality. To increase the systems performance the researcher found that implementing e-commerce systems is suitable way for SMEs in Jordan.

Hypothesis (6): stated that system design positively affect user satisfaction and system performance. 
Through testing the Hypothesis (6), Design features were calculated to determine the overall design quality of each site the researcher found that system design has a positive role in the successful adoption of e-commerce system in SMEs in jordan. This result based on the facts that system design includes very attractive site, Clear use of color and background, Chance to preview content without registration/membership, Good signposts at all times, Different ways to get straight to where you want to go; Opportunity for customers/Users to give feedback. Based on the findings above, the system design affect on system quality.

Hypothesis (7): stated that user satisfaction positively affect system quality.

Hypothesis (8): stated that system performance positively affect system quality.

The results of the (One Way Anova), to test the hypothesis 7 and 8 were presented in previous section. Because the value is calculated at the level of $(\alpha \geq 0.01)$, the researcher rejects the alternative hypothesis and accepts the null hypothesis.

The previous results indicate that there are differences in the impact of user satisfaction and system performance on system in small and medium enterprises in Jordan. so, there are statistical significant differences between the user satisfaction and system performance in the interest of companies in various sectors. It appears from this analysis that there is a variation in adoption of e-commerce systems, the high and low adoption of e-commerce by SMEs in banking sector is not as great as the adoption in insurance sector and service sector, also there is wide variation between banking sector and manufacturing sector. The researcher believe that the variances in adoption between sectors due to the nature of the business in these sectors.

\section{Conclusions}

The results of this study indicate that even though a majority of respondents were male with ages ranging from 36 to 50 years, had a 4-year college and a master degree. Concerning the number of years a respondent had been with the firm. The results showed that a high percentage of the respondents have been in experience from 7-10years.Many respondents were of high rank in positions and believed that adoption comprehensiveness and flexibility model to assess the quality of e-commerce systems will improve these systems. In addition, other attributes, such as technical attributes, managerial attributes, and human interface attributes had influence on the decision to adopt this type of e-commerce systems. Other reasons for adoption this model by a majority of respondents included the suitability with how the company did business, improving customer service and marketing, reaching new customers, increasing revenues, improving competitiveness, improving operational efficiency, improvement in inventory management or gaining a higher degree of control in managing the organization.

Significance testing was used in the analysis of each of the hypotheses. The purpose of these hypotheses was to identify the effect technical attributes, managerial attributes, and human interface attributes on service quality, system transaction and system design. The researcher found significant statistical support for these hypothesis that a majority of respondents agreed with the statement that (technical attributes, managerial attributes, and human interface 
attributes) are a possible reason which might have motivated the organization to evaluate e-commerce systems, for example The respondent appeared to be an aware of how e-commerce can be used to enhance the operations, improve supply chain management, improve lead times, improve business processes, improve the relations with business partners, enhance our distribution process, and gave them higher degree of control in managing their organizations.

\section{Recommendations and suggestions for future research}

The findings of this study may be of practical importance to those academic, governmental, business, and community-based organizations whose purpose is to help and improve the productivity and competitiveness of SMEs. Managers and presidents of SMEs, who increasingly find themselves beleaguered by global competition, would be well served by becoming informed and educated about the powerful cost-effective capabilities of using e-commerce systems for transactions and for managing back-office operations, including supply chain management through implementation of a comprehensive e-business models.

It is recommended that future research be expanded to include more sectors of the Jordan economy, including retail, and agriculture. The study of all sectors may contribute to a more complete picture of evaluate this model.

It is recommended that future research be conducted into the current level of understanding by SME presidents and managers about the use of e-commerce systems beyond the establishment of Web sites, including their level of understanding about terms such as Service quality, system transaction, and system design.

Finally, it is recommended that future research be conducted to determine what the most effective means are to educate, inform, and motivate the Presidents, Owners, and managers of SMEs to take a proactive stance with regard to use and evaluate e-commerce system for business solutions.

\section{References}

Abanumy A., Al-Badi A., \& Mayhew P.,( 2005) e-Government Website Accessibility: In-Depth Evaluation of Saudi Arabia and Oman. The Electronic Journal of e-Government, 3(3), 99-106.

Abdel-Hamid, aurab. (2005). Problematic quality of the information in the websites. Arab magazine 3000. The Arab Club of information, 9-25.

Abdul Muti, Yasser. (2005). Marketing information in the face of competing information and resources diminish, Arab magazine 3000. The Arab Club of information, 39-54.

Albuquerque, A.B., \& Belchior, A.D. (2002). E-commerce Website quality evaluation, Euromicro Conference. Proceedings, 28, 294-300.

Antonia Stefani1, Dimitris Stavrinoudis1, \& Michalis Xeno. (2007). In-Depth Analysis of Selected Topics related to the Quality Assessment of e-Commerce Systems. In e-Business and Telecommunication Networks, II, ISBN: 978-3-540-75992-8, 39-48. 
Antonia Stefani, Michalis Xenos, \& Dimitris Stavrinoudis. VECIMS. (2003). International Symposium on Virtual Environments, Human-Computer Interfaces, and Measurement Systems Lugano, witzerland,.

Barnes S., \& Vidgen R. (2001). Assessing the Quality of Auction Web Sites, in Proceedings of the 34th International Conference on System Sciences.

Bidgoli, H. (2002). Electronic Commerce Principles and Practice, Academic Press. San Diego.

Chalabi, Jamal, \& Al-Otaibi, khetam. (2005). The impact of globalization in the education information sector in Jordan. Social affairs, 9-33.

Chen, L., Gillenson, M., \& Sherrell, D. (2004). Consumer Acceptance of Virtual Stores: A Theoretical Model and Critical Success Factors for Virtual Stores. The DATA BASE for Advances in Information Systems, 35(2).

Choudrie J., Ghinea G., \& Weerakkody V. (2004). Evaluating Global e-Government Sites: A View Using Web Diagnostic Tools. Electronic Journal of e-Government, 2(2), 105-114.

Gharib, Magda Izzat. (2006). University library sites on the Internet: a comparative study of the sites of some libraries. Arab and Western (1). Cybrarians Journal.

Defallah, Ahmed. (2005). Workshop digital content Arab: reality and prospects and development echanism. The Arab Club of information, 11-12, 181-188. Tunisia.

Egger, F. (2001). Affective Design of E-Commerce User Interfaces: How to Maximise Perceived Trustworthiness, International Conference on Affective Human Factors Design. Asean Academic. London.

Elfriede, D., \& Rashka, J. (2001). Quality Web Systems, Performance Security, and Usability, Addison - Wesley. New York.

Etnoteam s.p.a.marzo. (2000). Evaluating and designing the quality of websites (a quality model for Websites) university of Milan.

Julian, T., \& Standing, C. (2003). The value of User Participation in the E-Commerce Systems Development, Informing and IT Education Conference, Pori, Finland.

Henfridsson, O., \& Holmstrom, H. (2003). Developing E-commerce in Internetworked Organizations: A Case of Customer Involvement Throughout the Computer Gaming Value Chain. The DATA BASE for the Advances in Information Systems, 33(4).

Hoi-Yan Ma,T., \& Zaphiris, P. (2003). The Usability and Content Accessibility of the E-government in the UK. In C. Stephanidis (Ed.), Universal Access in HCI, pp. 760-764. Lawrence Erlbaum, Mehwah, USA.

Luis Olsina Santos. (1999). Web-site Quality Evaluation Method: a Case Study on Museums. ICSE 99 - 2nd Workshop on Software Engineering over the Internet. 
Krauss K. (2003). Testing an e-Government Website Quality Questionnaire: A Pilot Study, in Proceedings of the 5th Annual Conference on World Wide Web Applications (WWW2003).

Lautenbach M. A. E, Schegget I. S., Schoute A. M., \& Witteman C. L. M. (2008). Evaluating the Usability of Web Pages: A Case Study, available at: http://www.phil.uu.nl/preprints /ckipreprints/PREPRINTS /preprint011.pdf.

Mich Ie, Franch M., \& Gaio L. (2003).Evaluating and designing the quality of websites. IEEE, Multimedia, Jan-march, 34-43.

Nielsen, J. (2000). Designing Web Usability: The Practice of Simplicity, New Riders Publishing. Indianapolis. Indiana.

Oreste Signore. (2005). A Comprehensive Model for Web Sites Quality, Seventh IEEE International Symposium on Web Site Evolution - Budapest, Hungary - September 26, ISBN 0-7695-2470-2, 30-36. http://dx.doi.org/10.1109/WSE.2005.1

Omar, Iman Fawzi. (2006). Ways tests the ability to use libraries Usability Testing sites on the Internet. Cybrarians Journal.

Sauro, J., \& Kindlund, E. (2005). A Method to Standardize Usability Metrics Into a Single Score, CHI2005 Methods and Usability, Portland, Oregon, USA.

Sean Quan Lau. (2006). Domain Analysis of E-Commerce Systems Using Feature-Based Model Templates, A thesis, Waterloo, Ontario, Canada.

Shaw, N., DeLone, W. (2002). Sources of Dissatisfaction in End- User Support: An Empirical Study. The DATA BASE for Advances in Information Systems, 33(2), http://dx.doi.org/10.1145/513264.513272

Slyke, C., Belanger, F., \& Comunale, C. (2006). Factors Influencing the Adoption of Web Based Shopping: The Impact of Trust. The DATA BASE for Advances in Information Systems, 35(2).

Singh I., \& Sook A. (2002). An Evaluation of the Usability of South African University Web Sites, in Proceedings of the 2002 CITTE Conference, Durban, South Africa.

Wendy Cukler Catherine A. Middilton. (2003). Evaluating the web precence of voluntary sector organizations: An Assessment of Canadian Web Sites, IT \& Society, Volume 1, ISSUE 3, PP. 102-130.

Wolfinbarger, M., \& Gilly, M. (2000) Consumer motivations for online shopping. Proceedings of the Americas Conference on Information Systems. Long Beach, CA: Association for Information Systems, pp. 1362- 1366.

Youngsu Lee, \& Jinwoo Kim. (2005). From Design Features to Financial Performance for Online Stock Trading Sites

Zwass, V. (1996). Structure and macro-level impacts of electronic commerce: from technological infrastructure to electronic marketplaces. International Journal of Electronic Commerce, 1. 